\title{
The Role of Fat in the Diet of Rats
}

\section{Influence of Kind and Quantity of Fat on Food and Fluid Consumption and Urine Production}

\author{
By E. AAES-JØRGENSEN AND H. DAM
}

Department of Biochemistry and Nutrition, Polytechnic Institute, Copenhagen

(Received 27 February 1954)

In the early work of Burr \& Burr (1930) it was found that water consumption was increased, whereas calorie intake and urine production were unchanged, in rats reared on a fat-free diet. Wesson \& Burr (193I) investigated the metabolic rate of fatdeficient rats and found an increase in basal metabolic rate. The basal respiratory quotient was normal (0.9I), but in the first hours after a carbohydrate feed it was often well above unity, clearly indicating the formation of fat from carbohydrate by rats in various stages of the fat-deficiency disease. As no relief was obtained from the signs of the fat-deficiency disease by the fat thus formed from carbohydrate, it was concluded that the curative linoleic and linolenic acids were formed by the rat neither from the carbohydrate nor from the fat. Burr \& Beber (I937) did not find the fat-deficient rats more active than their controls. Their metabolic rates calculated as Cal./sq.m of surface were much higher than those of the control animals. Ramalingaswami \& Sinclair (195I) found increased water consumption and normal or slightly diminished urinary output and no haematuria in fat-deficient rats. The water contents of the tissues showed that the excess water was not retained.

In the experiments to be described the effects of various fats on food and fluid intake and urine production were measured. Growth rates obtained by feeding these diets have already been described (Aaes-Jørgensen \& Dam, I954b).

\section{EXPERIMENTAL}

The animals and diets used in this experiment were the same as previously reported (Aaes-Jørgensen \& Dam, 1954 $b$ ).

Food and fluid consumption were measured for all groups through the last $\mathrm{I} 3$ weeks of the experiment. Urine was collected as described earlier (Aaes-Jørgensen \& Dam, $1954 a$ ). Each of the animals was left over the collecting funnel for $48 \mathrm{~h}$, during which time urine production and food and fluid consumption were measured.

\section{RESULTS AND DISCUSSION}

Table $\mathrm{r}$ shows the average food and fluid consumption for the different groups through the last 6 weeks of the experiment.

Fluid intake per sq.m body surface per day. From Table $\mathrm{I}$ it is seen that on diets with $7 \%$ lard, peanut oil or coconut oil as dietary fat and water as drinking fluid (groups IO, I4 and 26 , respectively) the water consumption per sq.m surface was fairly constant. 
An increase in the level of extracted casein in the lard diet from 20 to $30 \%$ (groups to and 20) did not influence water consumption.

With increasing amounts of lard ( 7,14 and $28 \%$, groups 10,16 and 18$)$ a decrease in water intake was observed.

Table I. Mean values for weight, surface area, food, fuid and calorie intake for groups of six rats during the last 6 weeks of the experiment

\begin{tabular}{|c|c|c|c|c|c|c|c|c|}
\hline \multirow{2}{*}{$\begin{array}{c}\text { Group } \\
\text { no. }\end{array}$} & \multirow{2}{*}{ Diet characteristics } & \multirow{2}{*}{$\begin{array}{l}\text { Weight } \\
\text { (g) }\end{array}$} & \multirow{2}{*}{$\begin{array}{l}\text { Surface } \\
\text { area* } \\
\text { (sq.cm) }\end{array}$} & \multicolumn{2}{|c|}{ Fluid intake/day } & \multirow{2}{*}{$\begin{array}{l}\text { Food in- } \\
\text { take/day } \\
\quad(g)\end{array}$} & \multicolumn{2}{|c|}{ intake/day } \\
\hline & & & & $\mathrm{ml}$. & $\mathrm{ml} . / \mathrm{sq} \cdot \mathrm{m}$ & & Cal. $†$ & Cal./sq.m \\
\hline IO & $7 \%$ lard, water & I 88 & 379 & 25.5 & 673 & 10.6 & $43 \cdot 4$ & II45 \\
\hline II & $7 \%$ lard, raw skim milk & IgI & 383 & $36 \cdot 5$ & 953 & 6.8 & $40 \cdot 3$ & 1052 \\
\hline 12 & $\begin{array}{l}7 \% \text { hydrogenated pea- } \\
\text { nut oil, water }\end{array}$ & 162 & 343 & 34.4 & 1003 & II 2 & $45^{\circ} 8$ & 1335 \\
\hline $\mathbf{r}_{3}$ & $\begin{array}{l}7 \% \text { hydrogenated pea- } \\
\text { nut oil, raw skim milk }\end{array}$ & I 74 & 360 & $40 \cdot 3$ & III9 & 8.0 & $48 \cdot 7$ & $\mathbf{1 3 5 3}$ \\
\hline$I_{4}$ & $7 \%$ peanut oil, water & 192 & 385 & $24 \cdot 3$ & $63 \mathrm{I}$ & $x 0.6$ & $43 \cdot 4$ & 1127 \\
\hline I5 & $\begin{array}{l}7 \% \text { peanut oil, raw } \\
\text { skim milk }\end{array}$ & 233 & 438 & $40 \cdot 6$ & 927 & $9 \cdot 4$ & $52 \cdot 3$ & I 194 \\
\hline I6 & $14 \%$ lard, water & 187 & 378 & $22 \cdot 4$ & 593 & 10.8 & $47 \cdot 9$ & 1267 \\
\hline 17 & $\begin{array}{l}\text { r4\% hydrogenated pea- } \\
\text { nut oil, water }\end{array}$ & 160 & $34 \mathrm{I}$ & $34 \cdot 3$ & 1006 & $I x \cdot 7$ & $52{ }^{\circ} 0$ & r 525 \\
\hline 18 & $28 \%$ lard, water & I95 & 389 & 20.5 & 527 & $7 \cdot 9$ & $43^{\cdot} \mathrm{I}$ & I 108 \\
\hline 19 & $\begin{array}{l}28 \% \text { hydrogenated pea- } \\
\text { nut oil, water }\end{array}$ & 139 & 310 & $32 \cdot 6$ & 1052 & $8 \cdot 9$ & $45 \cdot 9$ & $148 \mathrm{I}$ \\
\hline 20 & $\begin{array}{l}7 \% \text { lard, } 30 \% \text { casein, } \\
\text { water }\end{array}$ & I9I & $3^{83}$ & 25.9 & 676 & 10.6 & $43^{\cdot 6}$ & ${ }_{113} 8$ \\
\hline $2 \pi$ & $\begin{array}{l}7 \% \text { hydrogenated pea- } \\
\text { nut oil, } 30 \% \text { casein, } \\
\text { water }\end{array}$ & I75 & $3^{62}$ & $32 \cdot 9$ & 909 & 10.9 & $44 \cdot 8$ & 1238 \\
\hline 22 & $\begin{array}{l}\text { No fat, ro } \% \text { casein, } \\
\text { water }\end{array}$ & 96 & 242 & $21 \cdot 4$ & 884 & $10 \cdot I$ & $37 \cdot 7$ & r 558 \\
\hline 23 & $\begin{array}{l}\text { No fat, } 20 \% \text { casein, } \\
\text { water }\end{array}$ & I53 & 330 & 30.5 & 924 & I3. I & $49 \cdot 3$ & 1494 \\
\hline 24 & $\begin{array}{l}\text { No fat, } 30 \% \text { casein, } \\
\text { water }\end{array}$ & 158 & 338 & $31 \cdot 9$ & 944 & II $\cdot 4$ & $43 \cdot 0$ & 1272 \\
\hline 25 & $\begin{array}{l}7 \% \text { hydrogenated } \\
\text { whale oil, water }\end{array}$ & $16_{3}$ & 345 & $32 \cdot 2$ & 933 & $I I \cdot 4$ & $46 \cdot 9$ & 1359 \\
\hline 26 & $7 \%$ coconut oil, water & 188 & 379 & $25 \cdot 5$ & 673 & II'I & $45 \cdot 4$ & $1 \pi 98$ \\
\hline
\end{tabular}

* The surface area was calculated by the formula: surface area (sq. $\mathrm{cm}$ ) $=\mathrm{II} \cdot 36^{\sqrt[3]{ }} \sqrt{W^{2}}$ (where $W=$ weight in g) (Harte, Travers \& Sarich, 1948; Brody, 1945).

$\uparrow$ Calculated by assuming that protein and carbohydrate yield $4 \mathrm{Cal} / \mathrm{g}$ and fat $9 \mathrm{Cal} / \mathrm{g}$.

When hydrogenated peanut oil was fed at a $7 \%$ level (group I2), water intake was greater than with $7 \%$ lard (group ro). This is in accordance with the results described earlier (Aaes-Jørgensen \& Dam, 1954a). A similar increase was seen when the group receiving $7 \%$ hydrogenated whale oil (group 25) was compared with the $7 \%$ lard group (group ro). Increase of the casein content from 20 to $30 \%$ in a diet with $7 \%$ hydrogenated peanut oil decreased water consumption somewhat (groups 21 and I2).

Increase of hydrogenated peanut oil in the diet from 7 to 14 and $28 \%$ (groups 12 , I 7 and 19 ) led to only small variations in water intake. The fluid intake was very high in all three groups.

On fat-free diets (groups 22-24) water intake per sq.m. surface increased perhaps slightly with increasing casein content in the diet. It was clearly higher than that N जाI 3 
found for animals on the $7 \%$ lard diet (group 10), but a little lower than that of animals on hydrogenated peanut-oil diets (groups 12,17 and 19 ).

Fluid consumption was always higher with raw skim milk in place of watergroup I I compared with group Io (lard diets), group I3 compared with group I2 (hydrogenated peanut-oil diets) and group 15 with group 14 (peanut-oil diets). Further, of the animals given raw skim milk those on the hydrogenated peanut-oil diet (group I3) consumed the greatest quantities of fluid.

From Table $\mathrm{I}$ it is seen that with raw skim milk instead of water, food intake, calculated as grams of food eaten, decreased. These observations, like those of Harte et al. (1948), confirm the general assumption that animals consume as much solid and liquid food as is necessary for maintenance of a normal metabolic rate.

It should be emphasized that there were fairly large variations between individual groups in the total calorie intake calculated as calories per surface unit per animal. These variations will be further discussed in relation to the results presented in Table 2.

Urine production in relation to the various diets and drinking fluids is shown in Table 2. The results are the mean values of measurements on individual animals in each group for 2-day periods during the last 6 weeks of the experiment.

The experimental error of the measurements in Table 2 was greater than that of the corresponding figures in Table $\mathrm{I}$ because the figures in Table 2 are averages of measurements for only $48 \mathrm{~h}$ per animal, whereas the figures in Table I represent average values for the different groups for 6 weeks. However, comparison of Tables I and 2 suggests the same general patterns of response.

Urine production per sq.m body surface per day. From Table 2, it is seen that urine production was about the same on diets with $7 \%$ lard, peanut oil or coconut oil (water as drinking fluid) (groups I0, I4 and 26). Increase in the casein content from 20 to $30 \%$ on the lard diet (group 20) seemed to have increased the urine production a little compared with that of group 10. The water uptake was also about the same in these groups.

On diets with increasing contents of lard (from 7 to 14 and $28 \%$, groups Io, 16 and 18 ), urine production became lowest in group 18 , and water intake was simultaneously decreased in this group.

With hydrogenated peanut oil or hydrogenated whale oil at a level of $7 \%$ (groups I2 and 25), and water as drinking fluid, a marked decrease in urine production was seen compared with that of group Io ( $7 \%$ lard). At the same time there was a clear-cut increase in water consumption. On a diet with $7 \%$ hydrogenated peanut oil and $30 \%$ casein (group 21 ) the same tendency was seen, but not as markedly.

On diets with $7, I_{4}$ and $28 \%$ hydrogenated peanut oil and water (groups $12, I_{7}$ and I9) urine production decreased with increasing dietary fat level. Water intake was remarkably increased compared with that of the corresponding lard groups (groups 1o, 16 and 18 ).

In the groups on the fat-free diets and water (groups 22-24) urine production was markedly decreased, compared with that of group 10 ( $7 \%$ lard). The water consumption was extraordinarily high in the fat-free groups. 
ปั)

若若造

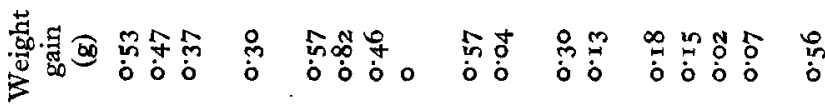

क

章

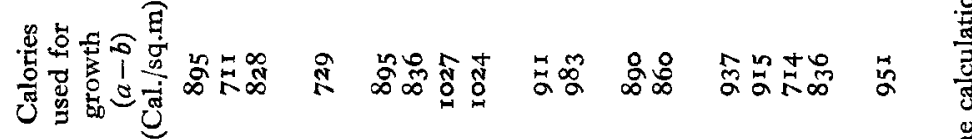

3

:

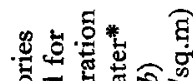

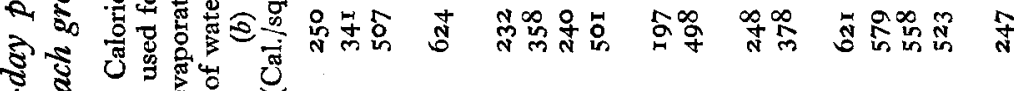

i

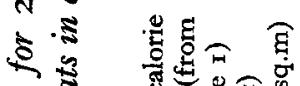

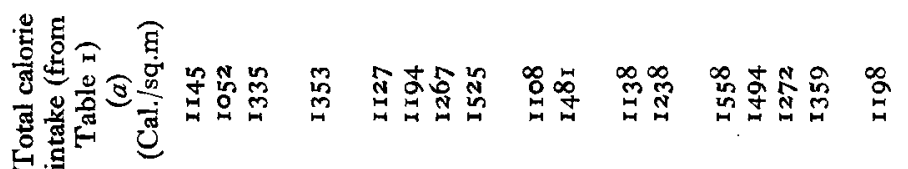

ن̈.

10

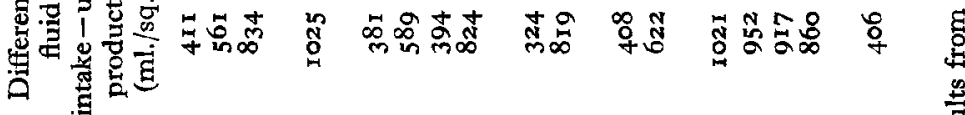

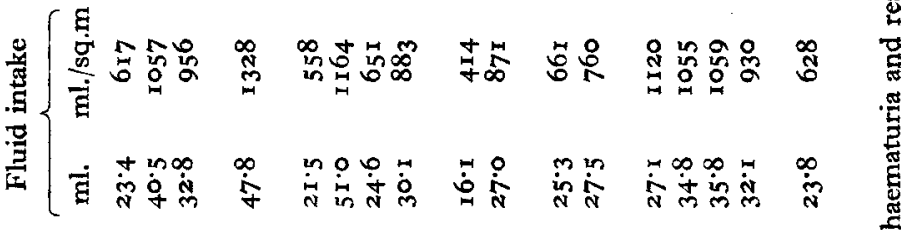

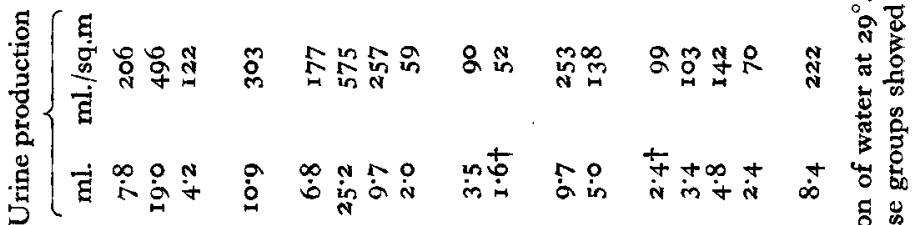

.

赵

.

है ङ

डิ

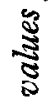

홍

కั

.

辂

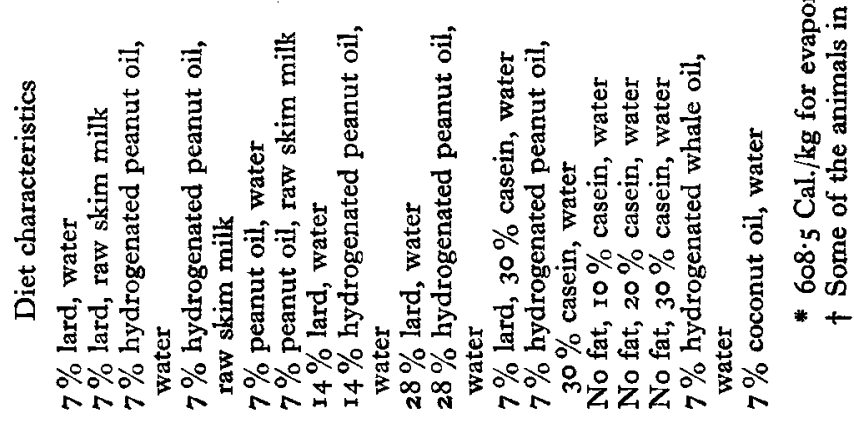

$\frac{5}{0}$
n 
Raw skim milk as drinking fluid increased urine production when compared with that of the groups on the corresponding diets and water. Of all the groups given raw skim milk the one on the diet with $7 \%$ hydrogenated peanut oil (group I3) had the lowest urine production and the highest intake of raw skim milk.

Ramalingaswami \& Sinclair (I95I) found, like Burr \& Burr (I930), a normal or a slightly diminished urinary output in fat-deficient rats. In the present experiment urine production was remarkably low on diets containing hydrogenated fat and on fat-free diets. Coconut oil gave the same picture as lard and peanut oil in this respect. Raw skim milk as drinking fluid generally increased urine production, but again the animals on the hydrogenated peanut-oil ration had a lower urine output than animals fed lard or peanut oil.

These results showed that the urine production of the animals on diets with hydrogenated peanut oil, hydrogenated whale oil and fat-free rations was decreased alongside with an increase in fluid intake compared with the animals on lard, peanut or coconut-oil diets, i.e. the difference between fluid intake and urine output was large in these groups (Table 2). When raw skim milk was given instead of water (groups II, $I_{3}$ and $r_{5}$ ) this difference was somewhat greater on the diets containing lard and peanut oil (groups II and I5). On hydrogenated peanut oil the difference was exceedingly high.

A parallelism between growth rate and difference in fluid intake and urine output is found on comparing the data from Tables I and 2. Slow growth was always found when the difference between fluid intake and urine production was great. These findings indicate that the excess fluid was eliminated from the body.

Further, the animals on the lard, peanut-oil and coconut-oil diets had about the same calorie intake. The calorie intake per surface unit per animal per day in the groups fed hydrogenated peanut oil, hydrogenated whale oil or the fat-free diets was remarkably increased. This increase in the calorie intake paralleled poor growth (Table I), increased fluid intake and decreased urine production (Table 2).

The figures in the last columns of Table 2 represent an approximate calculation of the calories used per gram of weight gain, after subtraction of the calories needed for evaporation of the water (found as difference between fluid intake and output) from the total calorie intake. It was assumed that all the 'reduced' calories were used for growth. Sinclair (1952) assumed that the increased calorie intake in fat deficiency could be explained by the increased need of calories for evaporation of water. The figures in Table 2 indicate that the increased evaporation of water did not wholly explain the fact that animals on hydrogenated-oil or fat-free diets ate much and grew slowly.

Urines from the individual animals in all the groups of this experiment were examined for specific gravity, occurrence of blood, protein, ketone bodies and sugar; the $\mathrm{pH}$ was measured and the colour recorded.

When urine production was low, there was always an increase in its specific gravity, and the colour was darker (more yellow-brown) than normal. In some of the animals from groups $\mathrm{I} 9$ and 22 (28\% hydrogenated peanut oil and a fat-free diet, respectively) haematuria occurred in the last weeks of the experiment. Animals in the groups 
receiving raw skim milk had a slight galactosuria, but the specific gravity increased only little or not at all, probably because urine production in these animals was somewhat increased. Protein and ketone bodies were found in only few animals and were not limited to any particular group. The $\mathrm{pH}$ ranged from about $5 \cdot 60$ to $6 \cdot 90$. The principal impression was that the urine from the animals receiving raw skim milk was less acid ( $\mathrm{pH} 6 \cdot 20-6 \cdot 90)$ than that from the animals producing the more concentrated urine (around $\mathrm{pH} 5 \cdot 60-5 \cdot 90$ ).

During the experimental period the animals were inspected weekly. In the preliminary experiment (Aaes-Jørgensen \& Dam, 1954a) we did not find the classical skin signs of essential fatty-acid deficiency in the animals reared on a fat-free diet. We assumed that this was due to the high humidity of the animal room, as shown by Brown \& Burr (1936). Before beginning the present experiment, control of temperature and humidity was established. During the experimental period the temperature in the animal room varied from 23 to $25^{\circ}$ and the relative humidity from 45 to $55 \%$.

Animals on the fat-free rations (groups 22-24) showed scaly tail and dry and scaly skin, especially of the hind-legs. The fur was dishevelled and felt moist or greasy, particularly in the animals from group 22 (fat-free diet with ro\% casein) and to some extent in those from group 23 (fat-free diet with $20 \%$ casein). Some of the animals from group 24 (fat-free diet with $30 \%$ casein) had small wounds, especially in the back of the neck and on the shoulders.

Animals on diets with hydrogenated peanut oil (groups 12, 17 and 19) or hydrogenated whale oil (group 25) and water showed signs similar to those in the animals reared on fat-free diets.

No signs resembling the fat-deficiency syndrome were found in any of the animals in the other groups.

The relation of lack of essential fatty acids to skin and histological kidney lesions is discussed in a paper being prepared for publication elsewhere.

\section{SUMMARY}

I. Female rats were reared on diets with various amounts of fats during an experimental period of 16 weeks. Food and fluid consumption and urine output were measured throughout the last $\mathrm{I} 3$ weeks of the experiment.

2. Water intake was higher on diets with hydrogenated peanut oil or hydrogenated whale oil, and in absence of dietary fat than on diets with lard, peanut oil or coconut oil. Change of drinking fluid from water to raw skim milk resulted in a general increase of the fluid consumption, and the fluid intake was also greatest for the animals on hydrogenated peanut oil.

3. Urine production was lower on diets with hydrogenated peanut oil or hydrogenated whale oil or no fat than on diets with lard, peanut oil or coconut oil. Changing the drinking fluid from water to raw skim milk increased the diuresis generally. Again, the animals on the hydrogenated peanut-oil diet showed the lowest output of urine.

4. The greatest calorie intake per surface unit per day occurred in the animals on 
hydrogenated peanut oil or hydrogenated whale oil or with no fat in the diet. The animals in these groups also had the slowest growth rate.

5. The increased calorie intake could not be due merely to an increased evaporation of water in the animals reared on hydrogenated oil diets or fat-free diets.

6. The external signs of the animals fed hydrogenated peanut oil or hydrogenated whale-oil diets resembled the classical skin signs seen in animals on fat-free diets. Haematuria was found on the hydrogenated peanut-oil as well as on the fat-free ration.

\title{
REFERENCES
}

Aaes-Jørgensen, E. \& Dam, H. (1954a). Brit. F. Nutr. 8, 281.

Aaes-Jørgensen, E. \& Dam, H. (I954b). Brit. F. Nutr. 8, 285.

Brody, S. (1945). Bioenergetics and Growth. New York: Reinhold Publishing Co.

Brown, W. R. \& Burr, G. O. (x936). F. biol. Chem. rr4, xvi.

Burr, G. O. \& Beber, A. J. (1937). $\mathcal{F}$. Nutr. 14, 553.

Burr, G. O. \& Burr, M. M. (1930). F. biol. Chem. 86, 587.

Harte, R. A., Travers, J. J. \& Sarich, P. (1948). F. Nutr. 36, 667.

Ramalingaswami, V. \& Sinclair, H. M. (I95 I). Brit. F. Nutr. 5, x.

Sinclair, H. M. (1952). Symp. biochem. Soc. no. 9, p. 80.

Wesson, L. G. \& Burr, G. O. (I931). F. biol. Chem. 91, 525.

\section{The Role of Fat in the Diet of Rats}

\section{Influence of Supplementation with Raw Skim Milk, Linoleic Acid or both on Growth}

\author{
By E. AAES-JØRGENSEN AND H. DAM \\ Department of Biochemistry and Nutrition, Polytechnic Institute, Copenhagen
}

(Received 27 February 1954)

In continuation of previous studies, it was the purpose of the experiments reported here to study further the growth-promoting effect of raw skim milk, especially in connexion with hydrogenated dietary fat (Aaes-Jørgensen \& Dam, I954a,b), and further to compare the effect of raw skim milk with dietary supplements of linoleic acid. Young female rats were used because they require a smaller amount (about $20 \mathrm{mg}$ ) of linoleic acid/animal/day (Greenberg, Calbert, Savage \& Deuel, 1950), whereas the optimum level of linoleate required by fat-depleted male rats exceeds $200 \mathrm{mg} /$ day (Deuel, Greenberg, Anisfeld \& Melnick, 195 I). The latter workers stated further that the requirements of essential fatty acids are apparently increased with the concomitant ingestion of fat.

\section{EXPERIMENTAL}

Newly weaned female rats were distributed in twenty-four groups of six animals. In Table I is shown the composition of the diets used together with the drinking fluid given $a d$ lib. throughout the 18 weeks of the experiment. A transparent aqueous suspension of vitamins A and D (Decamin aquosum, Ferrosan Ltd., Copenhagen) 